\title{
Electoral Fraud or Violence The Effect of Observers on Party Manipulation Strategies
}

\author{
Joseph Asunka, Sarah Brierley, Miriam Golden, Eric Kramon, and George Ofosu*
}

September 8, 2016

* The William and Flora Hewlett Foundation (asunka@ucla.edu); Department of Political Science, University of California, Los Angeles (sabrierley@ucla.edu); Department of Political Science, University of California, Los Angeles (golden@ucla.edu); Department of Political Science, George Washington University (ekramon@gwu.edu); Department of Political Science, University of California, Los Angeles (ofosu@ucla.edu). We are grateful to Daniel de Kadt, Jennifer Doherty, Barbara Geddes, Danny Hidalgo, Theresa Kuhn, John McCauley, Galen Murray, Daniel Posner, Michael Ross, Michael Thies, Daniel Treisman, Lynn Vavreck, and Adam Ziegfeld for comments. We also received useful comments from audience members at a Workshop on Electoral Integrity, Violence, and Vote-Buying held at the Center on Democracy, Development, and the Rule of Law, Program on Poverty and Governance, Stanford University, April 12-13, 2013; at the American Political Science Association annual conference, Chicago, August 29-September 1, 2013; at the Working Group in African Political Economy, University of California at Berkeley, December 19, 2013; at the University of California at Los Angeles, February 4, 2014; at the Pacific Conference of Development Economics, Los Angeles, March 15, 2014; at a conference on Voting Experiments, University of Montreal, March 28-29, 2014; and at the University of Gothenburg conference on experiments in political science, May 7-8, 2015. We gratefully acknowledge the collaboration of our research partner in Ghana, the Centre for Democratic Development, as well as Ghana's Coalition of Domestic Election Observers. We also thank our 300 research assistants for data collection. Funding came from the U.K.'s Ghana office of the Department for International Development and a U.S. National Science Foundation Grant for Rapid Response Research (RAPID) SES-1265247 (Miriam Golden PI), as well as the UCLA Academic Senate, none of which bears responsibility for the results reported here. This research was approved by the University of California at Los Angeles IRB \#12-001543 on October 26, 2012. 


\begin{abstract}
We study the effects of domestic election observers on electoral fraud and violence. With an experimental research design and polling station data on fraud and violence during Ghana's 2012 elections, we show that observers reduce fraud and violence at polling stations to which they were deployed. We also argue that local electoral competition shapes party activists' response to observers. In single-party dominant areas, we expect parties to use their local political networks to relocate fraud to polling stations without an election observer. In contrast, we expect party activists to relocate violence to stations without observers in competitive areas - a response that requires less local organizational capacity. The results are consistent with these expectations, highlighting how local party organization and electoral incentives shape the manipulative electoral strategies employed by parties in democratic elections.
\end{abstract}


Electoral fraud and election-related violence undermine the quality of democratic elections. Existing data suggest that both are pervasive. One estimate suggests that major incidents of fraud affected about a quarter of elections held worldwide between 1980 and 2004. ${ }^{2}$ Electoral violence and voter intimidation are also widespread, especially in sub-Saharan Africa. ${ }^{3}$ Large-scale violence occurred in around 10 percent of all elections held in the region between 1990 and 2008, while violent harassment and voter intimidation were prevalent in about 38 percent of elections. $^{4}$

To combat fraud and election-related violence, domestic and international organizations routinely deploy election observers to monitor elections. ${ }^{5}$ In this paper, we examine the causal effects of domestic election observers on these two strategies of electoral manipulation in Ghana. We address two sets of questions about how observers impact election-day fraud and violence that occur in and around polling stations. First, we ask whether observers reduce fraud and intimidation at the polling stations that they monitor. Second, we investigate whether political parties respond to observers by shifting fraud or violence to polling stations without observers; that is, we examine whether observers have "spillover effects." By studying spillover effects and how they vary by strategy (fraud or violence) and by local political conditions, we are able to learn about the contexts in which political parties are likely to engage in electoral fraud or violence. Our analysis thus contributes to understanding how political parties select from the diverse "menu of manipulation" in different political environments. ${ }^{7}$

\footnotetext{
${ }^{2}$ Kelly 2011.

${ }^{3}$ Straus and Taylor 2012.

${ }^{4}$ Straus and Taylor 2012.

${ }^{5}$ Existing results show that observers reduce electoral fraud in a variety of settings. See, for
} example, Hyde 2011; Kelley 2012; Ichino and Schündeln 2012; Enikolopov et al. 2013; Sjoberg 2012.

${ }^{6}$ Spillover occurs when an intervention (treatment) targeted at one unit affects outcomes at other units that did not receive the intervention (control).

${ }^{7}$ Schedler 2012. 
Our theoretical framework emphasizes the role of local party activists in committing or coordinating electoral malfeasance. ${ }^{8}$ These activists commit electoral fraud in polling stations by, for example, voting multiple times, stuffing extra ballots into boxes, or co-opting local electoral officials to alter the final results. They are also often responsible for electoral violence and voter intimidation, engaging in it themselves or mobilizing others to do so. We highlight that electoral fraud and violence are shaped by the capacity and incentives of party activists. ${ }^{9}$ Since observers reduce both capacity and incentives at the polling stations that they monitor, we expect that they should therefore reduce electoral fraud and election violence in monitored stations. However, because capacity and incentives vary across local contexts, we expect that the response of party workers to observers will vary with the local partisan and electoral context. In single-party dominant areas where one party controls local politics and enjoys strong partisan connections to the population, parties have a greater capacity to shift fraud to polling stations without observers and less incentive to engage in violence. By contrast, in competitive areas, parties have less capacity to shift fraud to polling stations without observers and greater incentive to engage in violence and intimidation. Thus, we expect to see spillover effects related to fraud in single-party dominant areas and spillover effects related to violence in electorally competitive areas. ${ }^{10}$

We provide evidence for this with data from a field experiment conducted during Ghana's 2012 presidential and parliamentary elections. Ghana provides an excellent setting for this research for at least two reasons. First, Ghana's political system is characterized by the conditions that are expected to incentivize electoral fraud and election-related violence, including intense electoral competition $^{11}$ and a majoritarian, single-member-district electoral system. ${ }^{12}$ Indeed allegations of

\footnotetext{
${ }^{8}$ Weidmann and Callen 2013.

${ }^{9}$ Birch 2007; Weidmann and Callen 2013; Ziblatt 2009.

${ }^{10}$ In the context of our study, political parties have incentives to inflate vote tallies in any part of the country, including their party strongholds, as all votes count equally in the presidential race.

${ }^{11}$ Lehoucq 2002.
} 
fraud and instances of violence and intimidation have occurred in each election since the return to multi-party democracy in 1992. The results of the 2012 elections were challenged in Ghana's Supreme Court by the country's main opposition party on grounds of widespread fraud and irregularities. And although Ghana has not witnessed large-scale electoral violence, elections have been fraught with localized incidents of violent harassment and voter intimidation. ${ }^{13}$ Second, Ghana is characterized by substantial variation in partisan competition at the local level, which we leverage to test our hypotheses.

In line with past studies of election observers, ${ }^{14}$ our research design involves the random assignment of an election observer to each of over 1,000 polling stations located in four of Ghana's ten regions. ${ }^{15}$ Each observer is assigned to a single polling station, and is present from the opening of the polls to the conclusion of the public vote count at the end of the day. We also go beyond much of the existing literature on observers and implement a randomized saturation experimental design, ${ }^{16}$ detailed below, which allows us to estimate and account for spillover effects.

We study observers' impact on several indicators of electoral fraud and electoral violence. As a proxy for fraud, we use the voter turnout rate at each polling station in our sample. Although high turnout rates are not always indicative of fraud - though we record turnout rates of over 100 percent at about 4 percent of polling stations — turnout should not vary with the

\footnotetext{
${ }^{12}$ Birch 2007; Hicken 2007.

${ }^{13}$ Straus and Taylor 2012.

${ }^{14}$ Enikolopov et al. 2013; Hyde 2010; Ichino and Schündeln 2012; Sjoberg.

15 These four regions contain roughly 50 percent of the country's population, or about 12 million citizens. Constituencies are nested within regions. We present information on Ghana's administrative structure in Section 2.

${ }^{16}$ Baird et al. 2014.
} 
presence of a randomly assigned observer. If the turnout rate is lower in the presence of an observer, this suggests potential fraud at polling stations without observers. We also create indicators of fraud by coding a polling station as having suspiciously high turnout by examining significant deviations from mean and median turnout in individual constituencies. ${ }^{17}$ To measure polling station violence and intimidation, we use survey data we collect from election observers, as well as officials and party representatives at polling stations.

We find that election observers reduce electoral fraud and violence at the polling stations that they monitor. Regarding spillover effects, we find suggestive evidence that parties shift fraud to stations without observers in single-party dominant constituencies. We find no such displacement effect in competitive constituencies. By contrast, we find statistically strong evidence that parties move electoral violence to stations without observers in electorally competitive constituencies, while there is no evidence of this in single-party dominant areas. These patterns are consistent with our theoretical expectations.

Our study makes several contributions. First, our paper is one of the few to experimentally study electoral violence. Our study relates to Collier and Vicente, ${ }^{18}$ which experimentally examines the effects of an anti-violence campaign in Nigeria, and finds that the campaign reduced violence and increased voter turnout. We study the impact of a different program and investigate how parties move violence spatially in response to interventions designed to

${ }^{17}$ We use two approaches to identifying suspiciously high turnout. First, we define a station as recording a suspiciously high level of turnout if it recorded a turnout rate greater than two standard deviations from the average turnout rate in its constituency. Second, we code a station as suspicious if it recorded a turnout rate greater than the sum of the upper quartile of its constituency turnout rate and one-and-half times the interquartile range.

${ }^{18}$ Collier and Vicente 2013. 
reduce it. Our findings suggest that electoral violence is likely to occur in electorally competitive contexts, where parties lack the capacity or opportunity to engage in fraud.

Second, this paper is among the first to study electoral fraud and election-related violence in the same study. ${ }^{19}$ Our evidence adds to understanding how parties select from the diverse electoral manipulation strategies at their disposal in different contexts. ${ }^{20}$ Our contribution relates to Weidmann and Callen, ${ }^{21}$ who study how non-election violence in Afghanistan impacts electoral fraud. Our study is distinct in that we examine how parties use both electoral fraud and electoral violence to impact election results in a competitive democracy. Our paper also complements Bratton, ${ }^{22}$ which studies vote buying and violence in a Nigerian election, as well as Collier and Vicente and Robinson and Torvik, ${ }^{23}$ which predict the conditions where parties will engage in fraud versus violence.

Finally, we advance the literature on election observation in several ways. First, similar to Enikolopov et al., ${ }^{24}$ we focus on domestic rather than international observers, and provide evidence that domestic observers are able to reduce electoral fraud and violence. Second, the election observation literature to date has focused on the impact of observers on patterns of electoral fraud. In investigating both electoral fraud and violence, we provide a more complete account of how observers impact electoral manipulation.

${ }^{19}$ Fraud and violence are often studied in isolation. On fraud, see Beber and Scacco 2012; Deckert, Myagkov and Ordeshook 2011; Enikolopov et al. 2013; Hyde 2010; Lehoucq 2002; Lehoucq 2003; and Tucker 2007. On violence, see Hafner-Burton, Hyde and Jablonski 2014 and Wilkinson 2004.

${ }^{20}$ Schedler 2002; Collier and Vicente 2012; Robinson and Torvik 2009.

${ }^{21}$ Weidmann and Callen 2013.

${ }^{22}$ Bratton 2008.

${ }^{23}$ Collier and Vicente 2012; Robinson and Torvik 2009.

${ }^{24}$ Enikolopov et al. 2013. 


\section{Electoral Fraud, Violence, and the Impact of Election Observers}

Electoral fraud and violence may help to explain the mixed performance of formal democratic institutions around the world. Electoral fraud is problematic for democracy because it involves secret and illegal efforts to influence and distort election results. ${ }^{25}$ In this paper, we focus on election-day fraud that occurs at the level of the polling station. Instances of this form of fraud include unregistered voters casting ballots; multiple voting; stuffing the ballot box; and tampering with results at the close of polls. We focus on polling station fraud for a number of reasons. First, this is a form of fraud that can be widespread even in a competitive democracy, as our data corroborate. Second, political parties may be more likely to manipulate polls locally rather than nationally because of the limited scrutiny of local polls by journalists, opposition members, and the international community. ${ }^{26}$ Third, election observers are deployed on the day of an election to monitor polling stations and are therefore most likely to impact this type of fraud.

Electoral violence is equally problematic from the perspective of democratic accountability and representation as political parties typically use coercion and intimidation to demobilize and disenfranchise targeted populations. ${ }^{27}$ Violence was, as we have already noted, not uncommon in Africa in the last quarter century. Violent harassment and voter intimidation - phenomena which include harassment or intimidation of voters, police or other security forces breaking up rallies, fights between party supporters, and arrests of political opponents - were prevalent in 38 percent of elections held in the region during the same time period. Our focus in this paper is on violent harassment and voter intimidation, which the Straus and Taylor data show were prevalent during Ghana's 1992, 2004, and 2008 elections. $^{28}$

\footnotetext{
${ }^{25}$ Lehoucq 2003.

${ }^{26}$ Weidmann and Callen 2013.

${ }^{27}$ Bratton 2008; Collier and Vicente 2013; Wilkinson 2004.

${ }^{28}$ Straus and Taylor 2012.
} 


\subsection{Theoretical Expectations}

To engage in electoral fraud and violence, political parties often rely upon their local party activists, sometimes called party brokers. ${ }^{29}$ Together, these actors make up the local loyalty networks of the competing parties. ${ }^{30}$ In Ghana, political parties are organized as decentralized networks of these activists. Much like political parties in other democracies, and in particular like most clientelist parties, the parties are organized hierarchically. Their structure includes many layers, beginning at the level of the individual polling station and rising up to the constituency, regional, and national levels. ${ }^{31}$ Ghana's two major political parties both have organizational presence in all of the country's 275 electoral constituencies. Because in Ghana votes in the presidential contest count equally across the country, parties have strong incentives to maximize votes in all constituencies, regardless of the local level of electoral competition.

The most important role of the party activist is to mobilize and deliver votes. ${ }^{32}$ Party brokers are motivated by a combination of ideological and material considerations. Many voters in Ghana often have strong partisan attachments, ${ }^{33}$ and activists seek to advance the political agenda of their preferred party. Many brokers also seek career advancement in the party hierarchy: success as a party activist is perceived as a stepping stone toward candidacy for elected office or for a higher ranked party position. ${ }^{34}$ Since votes are counted in public at each polling station and then collated and reported at the constituency level, party leaders are able to evaluate the performance of their activists on election day.

Party activists are often the main perpetrators of election-day fraud. They commit fraud by

${ }^{29}$ Stokes et al. 2013.

${ }^{30}$ Weidmann and Callen 2013.

${ }^{31}$ Salih and Nordlund 2007.

${ }^{32}$ Osei 2012.

${ }^{33}$ Weghorst and Lindberg 2013.

${ }^{34}$ Bob-Milliar 2012. 
engaging in multiple voting, stuffing ballot boxes, or mobilizing ordinary citizens --- for example, by coercing underage citizens or foreign nationals to vote. Activists often also co-opt local election officials so that they turn a blind eye on fraudulent activities or agree to inflate vote tallies. ${ }^{35}$

To engage in violence and intimidation, party activists might act alone or enlist the services of vigilante groups — popularly known as "macho men" in Ghana ${ }^{36}$ — to intimidate voters, steal ballot boxes, and tear down campaign posters of opponents.

\section{Direct Effects of Observers}

We expect election observers to reduce electoral fraud and violence by affecting the incentives and capacity of party activists and electoral officials to engage in these illegal activities. ${ }^{37}$ Since observers monitor one polling station from the opening of the polls through the counting of votes, the presence of an observer substantially increases the likelihood that fraud or violence will be detected. Therefore, observers increase the potential costs of manipulative tactics and constrain opportunities for party activists to engage in them.

The costs created by observers can come in many forms. Since observers usually report irregularities and intimidation of voters to central officials, party activists may fear legal action should their actions be detected. A second cost could be reputational. Party brokers are often recruited from their local communities and may fear social sanctioning should their manipulation be exposed. The costs may also be psychological. Many people wish to avoid cheating in front of others. $^{38}$

Observers are also likely to constrain the capacity of local party activists to engage in fraud and violence. This is especially the case with respect to electoral fraud, as polling station fraud often depends on the co-optation of local electoral officials or on the complicity of ordinary

\footnotetext{
${ }^{35}$ Ziblatt 2009; Callen and Long 2015.

${ }^{36}$ Amankwaah 2013.

${ }^{37}$ Birch 2007; Weidmann and Callen 2013.

${ }^{38}$ Snyder 1987.
} 
people. The presence of an election observer likely diminishes the ability of party brokers to rely on these groups. Polling station officials, for example, face legal and reputational costs should they be found to facilitate ballot stuffing. They also risk losing access to government jobs in the future. Observers may also activate democratic norms, empowering citizens to speak out when they witness anti-democratic behavior. We therefore expect election observers to reduce the motivation and capacity of party activists and election officials to commit fraud and to engage in violence at the polling stations that are under observation.

H1: Observers will reduce fraud at the polling stations that they monitor.

H2: Observers will reduce violence and intimidation at the polling stations that they monitor.

\section{Local Political Context and the Spillover Effects of Observers}

Political parties are concerned about maximizing votes in the constituency or country as a whole. Political party activists engaged in illegal behaviorare therefore likely to respond to the presence of observers by shifting these activities to stations without observers. That is, observers may create spillover effects. The existing literature provides evidence consistent with this. For example, Ichino and Schündeln show that parties responded to observers by moving fraud to nearby but unmonitored registration centers in the same constituency during Ghana's 2008 voter registration process. $^{39}$ Observers may also deter fraud at unobserved polling stations, which Enikolopov et al. find in their study of Russian parliamentary elections. ${ }^{40}$ The literature has yet to investigate, however, how observers may impact patterns of violence.

Generally, networks of party activists coordinate a political party's response to election observers. Thus, the precise way that spillovers work will vary across contexts depending on the structure of party organization and the technologies used by party activists to share information. In Ghana, party activists sit at the bottom of each party's constituency level operation. Each

\footnotetext{
${ }^{39}$ Ichino and Schündeln 2012.

${ }^{40}$ Enikolopov et al. 2013.
} 
constituency has a constituency organizer, who is responsible for running the party's campaign in that constituency. At the more local level, each party elects Electoral Area (EA) and polling station organizers who coordinate the activities of party workers in each local area. ${ }^{41}$ Within these subconstituency networks, party activists can communicate with one another using cell phones to report which stations do and do not have observers. They can also travel the relatively short distances between polling stations in the same local area to communicate in person with party activists. EA organizers can also report information to the party's constituency organizer, who can transmit that information to other party activists in the constituency. Because election observers in Ghana monitor a single polling station for the entire day, it is possible for party activists to record information on the locations of observers and to coordinate a response.

We expect that the local electoral and partisan context conditions whether this response is likely to center on efforts to engage in fraud or to intimidate voters at polling stations without an election observer. The local context is important because it shapes the opportunities and incentive of parties to engage in fraud and violence. We distinguish single-party dominant areas from electorally competitive ones. For reasons that we outline below, these local contexts vary in the opportunities that they afford parties to shift fraud to polling stations without observers and in the incentives to engage in violence and voter intimidation.

Regarding opportunity, we expect that political parties will have greater opportunities to shift fraud to polling stations without observers in single-party dominant constituencies. In such contexts, ordinary people and electoral officials - themselves recruited from the local population — are likely to be strong supporters of the dominant party. They thus have little incentive to report fraud and are likely easier to co-opt. Where parties are politically dominant, they also often control resources that can be used to pressure electoral officials, and potentially even opposition party brokers, into compliance. Because, by definition, dominant parties enjoy widespread partisan support and control local politics across an entire constituency, their options for shifting fraud away from

\footnotetext{
${ }^{41}$ EAs are sub-constituency units that contain on average five polling stations.
} 
monitored polling stations are vast. When an observer arrives at one, there are many options for party activists to choose from if they seek to commit fraud.

In competitive areas, parties do not enjoy strong partisan support across the entire constituency. They also face greater oversight and monitoring by the competing party. Party activists may therefore have the opportunity to commit fraud at only a small number of polling stations in the constituency. When an observer arrives at one, the options available for strategic relocation are limited. Thus, while motivations to commit fraud might be higher in electorally competitive areas, ${ }^{42}$ the opportunities for parties to shift fraud in response to observers will be lower.

Although parties have more opportunities to shift fraud around in their stronghold areas, their incentives to engage in violence or intimidation in these areas would be low. Electoral violence and intimidation are typically tools to demobilize voters and to drive down the turnout of targeted populations. ${ }^{43}$ Single-party dominant areas are populated largely by supporters of the dominant party ${ }^{44}$ and the dominant party will have little interest in disenfranchising those who are most likely to vote for them. In addition, there are audience costs to violence. Since voters are normally averse to violence and it is easily observable, activists of the dominant party risk alienating their supporters in core areas if activists use electoral violence there. ${ }^{45}$ Thus, parties have less incentive to engage in voter intimidation in their strongholds. ${ }^{46}$

In electorally competitive areas, by contrast, parties have more incentive to engage in violence. One reason is that local party organizations are interested in getting a majority in both

\footnotetext{
${ }^{42}$ Lehoucq 2003; Molina and Lehoucq 1999.

${ }^{43}$ Bratton 2008; Collier and Vicente 2013; Wilkinson 2004.

${ }^{44}$ Fridy 2007; Weghorst and Lindberg 2013.

${ }^{45}$ Collier and Vicente 2012.

${ }^{46}$ This is not to suggest that there will be no voter intimidation in party strongholds. Rather, compared to electorally competitive areas, there are fewer incentives to engage in voter intimidation.
} 
presidential and parliamentary elections. In the presidential race, winning the constituency for the party can create opportunities for party activists and politicians in terms of jobs in the incoming administration. All else equal, party incentives to manipulate the election, using either fraud or violence, are therefore greater in competitive areas. ${ }^{47}$ Because observers limit opportunities for fraud and parties have limited capacity to move fraud around in response to them, we expect parties to respond to observers by engaging in violence, a tactic that requires far less organizational capacity and complicity of the local population. A second reason is that electorally competitive areas are more populated with the types of voters that parties are have incentives to target with violence. There is evidence from studies of African elections that suggest that parties often intimidate swing voters ${ }^{48}$ or weakly aligned supporters of the opposition. ${ }^{49}$ In Ghana, electorally competitive constituencies are home to large numbers of such voters. Thus, incentives to engage in violence and intimidation in response to observers are greater in competitive areas.

H3: In single-party dominant areas, parties will respond to observer presence by shifting electoral fraud to polling stations without observers.

H4: In electorally competitive areas, parties will respond to observer presence by shifting violence/voter intimidation to polling stations without observers.

\section{Ghana's Political Context}

Since its transition to democracy in 1992, Ghana has conducted increasingly competitive presidential and parliamentary elections every four years. Two of these elections (2000 and 2008)

\footnotetext{
${ }^{47}$ Lehoucq 2003.

${ }^{48}$ Robinson and Torvik 2009.

${ }^{49}$ Collier and Vicente 2012.
} 
resulted in alternations of executive office. In this paper, we focus on the 2012 presidential race. $^{50}$ Ghana is divided into ten administrative regions. There are 275 electoral constituencies nested within these regions. The president is elected in a majoritarian run-off system from a single national constituency. ${ }^{51}$ Although votes for the president are aggregated across the country, ballots are counted at individual polling stations at the close of polls and aggregated at the constituency level prior to transmission to the national office of the Electoral Commission. This procedure incentivizes local party activists to maximize the number of votes for their presidential candidates within their constituencies.

Ghana has a two-party system. The two major parties — the incumbent National Democratic Congress (NDC) and the opposition New Patriotic Party (NPP) — routinely capture the

${ }^{50}$ Although parliamentary and presidential elections are concurrent, ballots for each election are deposited into separate boxes and can be analyzed separately.

${ }^{51}$ In 2008, the presidential election went to a second round. Despite the possibility of a second round in 2012, both parties had incentives to engage in fraud in the first round that we study. Because there was no strong third party candidate running in the race, both parties could have reasonably expected to reach the 50 percent threshold, thereby avoiding a runoff. Given this, even a small amount of fraud in the first round could have pushed a party over the threshold, or helped to prevent the opposition from getting over the threshold. Indeed the incumbent, John Mahama, won the 2012 presidential election in the first round with 50.70 percent of the vote. The 2008 election was also extremely close - the NDC candidate captured 50.23 percent of the vote in the second round, and only 40,000 more votes than the NPP candidate. In the first round in 2008, the NPP candidate received more votes than the eventual winner in the second round, capturing 49.13 percent of the vote and missing the threshold by about 73,000 votes. Given how tight these margins are, both parties had incentives to engage in some fraud in the first round in 2012. 
vast majority of votes in presidential elections. In 2012, the two parties received over 98 percent of the presidential vote. The NPP and NDC are multi-ethnic and multi-regional in composition. However, each party has regions where its support is particularly concentrated: ${ }^{52}$ The NDC attracts the support of most voters in Volta whereas the NPP draws its strength from the Ashanti region.

Ghana's elections have routinely suffered from allegations of fraud and malpractices. ${ }^{53}$

Allegations of electoral irregularities prior to the December 2012 elections have been reported in each stage of the election process; during voter registration, on election day, and while votes are aggregated. In earlier elections, political parties alleged that the voter register was inflated with names of ghost voters, minors, and foreign nationals (from neighboring Togo and Côte d'Ivoire). ${ }^{54}$ On election day, allegations of malpractice often involve attempts by party activists to stuff ballot boxes, to vote multiple times by impersonating absent voters, or to vote at more than one polling station. A consequence of multiple voting and ballot stuffing is unreasonably high levels of turnout at polling stations. Turnout figures above 95 percent, for example, were recorded in five constituencies in Ashanti during the 2008 elections. ${ }^{55}$ The post-election petition presented to Ghana's Supreme Court by the opposition NPP in 2012 centered on allegations of unrealistically high turnout, with rates above 100 percent at 1,826 (7 percent) polling stations.

While Ghana has not experienced large-scale electoral violence, low intensity violence and voter intimidation have been prevalent in each national election held since $1992 .{ }^{56}$ According to Gyimah-Boadi and Brobbey, "Ghanaian elections have been fraught with extreme tension,

\footnotetext{
${ }^{52}$ Lindberg and Morrison 2008; Whitfield 2009.

${ }^{53}$ Jockers, Kohnert and Nugent 2010; Smith 2002.

${ }^{54}$ Ichino and Schündeln 2012.

${ }^{55}$ European Union 292009.

${ }^{56}$ Straus and Taylor 2012.
} 
including intimidation, organized thuggery, and sporadic flare-ups of interparty violence". 57

Politicians regularly enlist the services of vigilante groups to intimidate voters, and to snatch ballot boxes and destroy campaign posters of opponents. ${ }^{58}$ As Amankwaah notes, "macho men exist in the imagined national history ... of Ghanaian election-related violence as thugs, who [sic] political leaders commonly hire during elections to snatch ballot boxes and intimidate voters at polling stations in various places around the country". 59 Political parties often frame elections in military terms. Indeed one of the major political parties has established a "Heroes Fund" for party activists who sustain injuries during campaigns. ${ }^{60}$ Hate speech on local radio stations has also created tensions and led to pockets of violent clashes during national elections. ${ }^{61}$

\subsection{Domestic Election Observers}

To promote clean elections, a coalition of civic organizations came together to observe the 1996 general elections. In 2000, the Coalition of Domestic Election Observers (CODEO) was formally established. Since then, CODEO has led domestic efforts to monitor elections. ${ }^{62}$ CODEO is widely viewed as non-partisan and independent. ${ }^{63}$

${ }^{57}$ Gyimah-Boadi and Brobbey 2012, p. 2.

${ }^{58}$ Jockers, Kohnert and Nugent 2010; Amankwaah

${ }^{59}$ Amankwaah 2013, 22-22.

${ }^{60}$ Ghana Web (2010, Jaunary 1). Aseidu Nketiah to establish NDC heroes' fund. Retrieved from http://www. ghanaweb.com/GhanaHomePage/NewsArchive/artikel.php?ID=174506 (last accessed on 12 September 2014.)

${ }^{61}$ Frazer and Gyimah-Boadi 2011.

${ }^{62}$ CODEO is composed of roughly 40 professional, religious, and civic advocacy organizations. The Ghana Center for Democratic Development, a governance research think-tank, is CODEO's secretariat.

${ }^{63}$ Boafo-Arthur 2006. 
The Electoral Commission of Ghana accredits election observers. Accreditation gives observers the right to access and observe proceedings at any polling station or vote aggregation center. All observers swear a public oath to act impartially and support the conduct of free and fair elections. Each observer is assigned to one polling station that she observes from the opening to the close of polls. Observers also remain on site for the public vote count that takes place at the end of the day at each polling place. Uniforms (i.e., official CODEO t-shirts and caps) ensure that observers are easily identifiable to election officials and voters. At polling stations, election observers usually position themselves away from other officials and party agents. Throughout the day, they report to a national co-ordination center using text messages. If an observer reports a serious incident of fraud, misuse of equipment, or violence, CODEO uses its communication structure to alert appropriate legal and security officials. CODEO also releases press statements throughout the day, as well as in the days and weeks following the close of polls.

\section{Research Design}

To estimate the effects of election observers on fraud and violence, we implement a randomized saturation experimental design. ${ }^{64}$ This section details the design.

\subsection{Sampling}

We conduct the study in four of Ghana's 10 regions: Ashanti, Central, Volta, and Western. These regions are located in the southern part of the country. ${ }^{65}$ Each region is divided into political constituencies, from which Members of Parliament are elected. We selected these regions

\footnotetext{
${ }^{64}$ Baird et al. 2014.

${ }^{65}$ Practical considerations limited the study to four regions. In addition, as we discuss elsewhere, the four regions represent the full range of political competitiveness in Ghana.
} 
because they vary in their degree of electoral competitiveness. Ashanti and Volta are the historic strongholds of the two major political parties, while Central and Western are electorally competitive. Historical voting patterns illustrate the variation in electoral competition across these constituencies. In the 2008 elections, the NPP won 73 percent of the vote in its stronghold, Ashanti, while the NDC's vote share in that region was 26 percent. In Volta, the NDC stronghold, the NDC won 83 percent of the vote in 2008, while the NPP won 15 percent. Western and Central, by contrast, were far more competitive. In Central, the NDC's vote share was 51 percent and the NPP's vote share was 46 percent. In Western, the NDC won 46 percent and the NPP won 50 percent.

We hypothesized that a party's response to observers may be conditioned by local electoral competition. Accordingly, we sample to get a mix of electorally competitive and non-competitive constituencies. We code a constituency as electorally competitive if the vote margin between the top two presidential candidates was less than 10 percentage points in the 2008 election, and noncompetitive otherwise. ${ }^{66}$ As spillover effects may also be affected by the physical distance between polling stations, we distinguish constituencies by their polling station density. We code a constituency as having a high polling station density when it has a higher than the median number of polling stations per square kilometer. ${ }^{67}$

There are 122 constituencies in our four study regions, and we randomly sample 60. Twentythree constituencies met our definition of electorally competitive. We sampled all of them. Of these, 12 have high polling station density and 11 have low polling station density. We then randomly selected 37 non-competitive constituencies, 18 from high and 19 from low polling station density constituencies. In the final stage of our sampling process, we randomly selected 30

\footnotetext{
${ }^{66}$ We measure electoral competition with data from the 2008 presidential elections. While a 10 percent margin might seem large in some contexts, it is a margin that is frequently overturned in Ghanaian elections. For those constituencies in which a different party won a majority in the presidential election in 2008 and 2004, the average margin of victory in 2004 was about 12 percent. ${ }^{67}$ The median is 0.14 polling stations per square kilometer.
} 
percent of polling stations in each of our 60 constituencies to form the sample.

\subsection{Two-Stage Randomization}

To assign treatment, we used a two-stage randomization process. In the first stage, we randomly assigned each constituency to one of three saturation levels: low, medium, and high. In the low condition, we treat 30 percent of sample polling stations with an observer. In the medium condition, we treat 50 percent of sample polling stations. In the high condition, we treat 80 percent. ${ }^{68}$ To ensure that we have different types of constituencies at each saturation level, we randomly assign these saturations within the four groups of constituencies discussed above. To improve our ability to precisely measure spillover effects, we assign the low condition with 20 percent probability and the medium and high conditions each with 40 percent probability. ${ }^{69}$ We denote the treatment condition of a constituency by $S$, where $s$ is equal to one of the three saturation levels. Online Appendix A shows the allocation of our 60 constituencies in each constituency type.

In the second stage, we randomly assigned polling stations to treatment or control. The probability of treatment is determined by the constituency-level observer saturation. For example, in the low condition constituencies, polling stations in the sample are treated with probability 0.3 . We denote polling station treatment status as $T$, where $t$ is equal to 1 (treated) or 0 (control).

This procedure yields a $3 \times 2$ experimental design. Our randomization process thus classifies polling stations into six groups: treated polling stations in low, medium, and high saturated constituencies, and control polling stations in low, medium, and high saturated

${ }^{68}$ Because we assign saturations within the sample of polling stations rather than within the population of stations in each constituency, the actual saturation rates of treatment is lower than these percentages suggest.

${ }^{69}$ The estimation of spillover effects relies on comparisons of control units in each of the three constituency level conditions. Since there are relatively few control stations in the higher saturation constituencies, we assign more constituencies to medium and high conditions. This increases statistical power to detect spillover effects. 
constituencies. There are a total of 2,310 polling stations in our sample. Online Appendix B provides evidence of covariate balance. ${ }^{70}$

\subsection{Assumptions}

Our framework relies on one central assumption: spillover effects will occur within constituency boundaries. This assumption is plausible given the structure of political parties in the country. Ghana's two major parties are organized hierarchically, with relatively independent party organizations operating at the constituency level. ${ }^{71}$ These constituency-level organizations are further organized into more localized networks of party activists. Given this structure, responses to observer presence are likely to be confined within constituency boundaries. ${ }^{72}$

Our design allows us to measure average spillover effects within constituencies without making any other assumptions about the structure of spillover. This approach is beneficial in our application because spillover effects are likely to take multiple forms. For example, party activists might shift manipulative strategies to control stations that are nearby (spatial spillover), or they might coordinate via cell phone to relocate malfeasance as far away as possible from observers within the same constituency. If we were to assume that spillovers were only spatial, we would miss the latter. The benefit of our design is that it allows us to measure all forms of spillover on average within a constituency.

\subsection{Estimation}

${ }^{70}$ Treated and control polling stations are comparable on a number of economic, demographic, and political variables. Constituencies assigned to low, medium, and high saturations are also comparable on these characteristics.

${ }^{71}$ Osei 2012.

${ }^{72}$ The same assumption was also made by Ichino and Schündeln in their paper on election fraud and observer spillover effects in Ghana. See Ichino and Schündeln 2012. 
Our unit of analysis is the individual polling station. ${ }^{73}$ In our framework, potential outcomes at the polling station level are determined by two factors: the individual station's treatment status (treatment or control); and the treatment condition of the polling station's constituency (low, medium, or high). Thus, potential outcomes can be written as follows:

$$
Y_{i j}\left(T_{i j}, S_{j}\right)
$$

where $Y_{i j}$ indicates fraud or violence at polling station $i$ in constituency $j . T_{i j}$ indicates the treatment status of polling station $i$ in constituency $j\left(T_{i j}=1\right.$ if an observer is present, and 0 otherwise). The constituency level treatment status is indicated by $S_{j}$, where $S_{j}=s$ and $s$ takes a value of low, medium, or high.

To estimate the direct effect of election observers, we first estimate the intention-to-treat (ITT) effect. We do so by comparing treated stations to control stations as follows:

$$
I T T=E\left(Y_{i j} \mid T_{i j}=1\right)-E\left(Y_{i j} \mid T_{i j}=0\right)
$$

Because of our randomization procedure, polling stations at different levels of $S_{j}$ are assigned

${ }^{73}$ While we could aggregate our data to the constituency level and compare averages across saturation levels, we do not do so in the main analysis for at least two reasons. First, treatment was assigned at the polling station level. Second, and more importantly, analyzing the data at the polling station level allows us to estimate both direct and spillover effects. Aggregating up to the constituency level would not allow us to disaggregate between observers' direct and spillover effects. Consider a hypothetical example in which we find that increasing the saturation of observers had no effect on constituency-level outcomes. In this situation, we would not be able to determine whether this was because observers have no direct effect and no spillover effect or because there was a lot of spillover that cancelled out any direct effect. For our purposes, distinguishing these scenarios is important. We therefore conduct the main analysis at the pollingstation level. 
to treatment with different probabilities. We therefore use inverse probability weighting when estimating the ITT. ${ }^{74}$

Equation 2 provides a preliminary estimate of the causal effect of observers but does not account for potential spillover effects. To account for spillover, we estimate the ITT conditional on the level of observer saturation. We refer to these quantities as $\operatorname{ITT}(s)$. The challenge in estimating $\operatorname{ITT}(s)$ is that we cannot simply compare outcomes at treated and control stations within the same saturation condition. In the presence of spillover, these estimates will be biased. Our solution, following Baird et al., is to compare outcomes at treated stations in each saturation level to control stations in constituencies assigned to the low saturation condition. ${ }^{75}$ We do this because the low saturation controls are the units least likely to be impacted by spillover effects.

Using control stations in low saturation constituencies to approximate "pure" control units — that is, units that are not exposed to spillover — is justified given the basic model of spillover that we expect is operating within constituencies. In this model, each observer will on average produce a similar spillover effect (if indeed there are spillover effects). The need for parties to shift fraud or violence to control stations results from their desire to reach a target level of manipulation in a constituency. ${ }^{76}$ Because election observers reduce parties' opportunity to engage in malfeasance at treated stations, parties will need to engage in more shifting as the saturation of observers increases in order to reach their target levels. As a result, control units will be more likely to be affected by

\footnotetext{
${ }^{74}$ Treated units are weighted by $1 / p$ where $p$ is equal to $0.8,0.5$, or 0.3 for polling stations in
} high, medium, and low saturation constituencies, respectively. Control units in high, medium, and low saturated constituencies have weights $1 /(1-p)$, where $p$ is equal to $0.8,0.5$, or 0.3 . ${ }^{75}$ Baird et al. 2014.

${ }^{76}$ The desired level of manipulation will, on average, be the same across the saturation conditions because we randomize saturation conditions across constituencies. 
spillover in constituencies with greater concentrations of observers. ${ }^{77}$

We thus estimate $\operatorname{ITT}(s)$ as follows:

$$
\operatorname{ITT}(s)=E\left(Y_{i j} \mid T_{i j}=1, S_{j}=s\right)-E\left(Y_{i j} \mid T_{i j}=0, S_{j}=\text { low }\right)
$$

We use inverse probability weighting to account for differences in treatment assignment probabilities across constituencies. The ITT $(s)$ estimates are our main quantities of interest. They provide estimates of the direct effect of observers at different observer saturation levels.

To test our hypotheses on potential displacement of fraud and violence from treated to control polling stations within constituencies, we estimate the average spillover effect on the nontreated stations, conditional on constituency-level saturation $(A S N T(s))$. Again, we use outcomes from control stations in low saturation constituencies as the baseline level of malfeasance that would occur had no observers been deployed within a constituency. To estimate average spillover effects, we compare outcomes in control stations at medium and high saturation levels to outcomes in control stations at low saturation. Formally, we estimate average spillover effects as follows:

$$
A S N T(s)=E\left(Y_{i j} \mid T_{i j}=0, S_{j}=s\right)-E\left(Y_{i j} \mid T_{i j}=0, S_{j}=l o w\right)
$$

If $\operatorname{ASNT}(s)>0$, and electoral malfeasance increases in control stations as observer saturation increases, this is evidence of a displacement effect. If $A S N T(s)<0$, violence and fraud decrease in control stations as observer saturation increases, which is evidence of a deterrence effect. If

\footnotetext{
${ }^{77}$ Control units in low saturation may have been subject to spillovers, and in this sense are not completely pure. Our decision not to have pure controls was both ethical and practical. CODEO's mission is to deter electoral malfeasance and enhance the quality of elections across the country. Part of their mandate is to have observers present in every constituency in Ghana. It was therefore neither practical nor appropriate to have constituencies with no observers.
} 
$A S N T(s)=0$, there is no evidence of spillover effects. To test hypotheses 3 and 4, we also estimate the $A S N T(s)$ in competitive and non-competitive constituencies.

\section{Measuring Fraud and Violence}

Our first indicator of fraud is polling station turnout. ${ }^{78}$ If turnout correlates with the placement of observers, this is evidence of fraud because it shows that turnout is artificially high at stations without observers. To construct this measure, we obtain data on the number of votes cast in each of our sample polling places using information from the official polling station results forms. Turnout is calculated as the total number of valid and rejected ballots divided by the number of persons registered to vote at the polling station. Since in Ghana voters are legally allowed to vote only at the polling station where they are registered, high levels of turnout at polling stations without observers suggests that multiple voting occurred, or that vote counts were artificially inflated. ${ }^{79}$ We also analyze two alternative indicators of potential fraud, coding polling stations as fraudulent when the turnout rate at a station appears to be an outlier in the constituency. We measure outliers in two ways. First, we code a station as being an outlier when turnout is more than two standard deviations above the constituency mean. Second, we code a station as being an outlier when recorded turnout is greater than the sum of the upper quartile of its constituency turnout plus one-and-half times the interquartile range (a standard approach to defining outliers in

\footnotetext{
${ }^{78}$ Fraud is difficult to measure. Previous authors have also measured election day fraud using turnout rates (see, for example, Enikolopov et al. 2013; Sjoberg 2012) as well as incumbent vote share (see Enikolopov et al. 2013; Hyde 2007, 2010; Sjoberg 2012) and changes in polling station results pre- and post-aggregation (see Callen and Long 2015).

${ }^{79}$ While in some countries security services and election personnel are able to vote at any polling station on election day, this is not the case in Ghana, where such personnel vote in an early election (i.e., Special voting). See the Public elections regulations (2012)(21).
} 
distributions). ${ }^{80}$

To measure election violence, we code whether a polling station experienced intimidation during voting. This outcome is one indicator from a survey that we conducted at each station in the sample. At treated stations, the information we use was reported by CODEO observers as part of their official duties. At control stations, our enumerators completed the same instrument that CODEO observers used to report activities at their assigned polling stations. To complete the survey, enumerators interviewed party agents and polling station officials. ${ }^{81}$ To avoid "observing" control stations, we could not send enumerators to control stations during the election process. We provided identical training to enumerators as received by CODEO observers. The question wording is as follows: "Did anyone attempt to harass or intimidate voters of polling officials during voting?" Possible responses to this question were Yes or No.

As we note, data for our violence indicator was collected using reports from two different sets of actors - election observers (treated stations) and party agents (control stations). The correlation between our treatment and data collection method is a potential concern as it could be a difference in the data collection procedure, rather than the impact of treatment, that drives differences we observe between treatment and control groups. There are at least two reasons why this should not be a major concern. First, if there is bias generated by the differences in data collection procedures, it is likely to be biased against the study hypotheses. For example, there is no reason to believe that election observers will be less likely to report intimidation at polling

\footnotetext{
${ }^{80}$ Moore and McCabe 2004.

${ }^{81}$ By law, political parties are allowed to place agents in each polling station to observe the proceedings. These agents are usually not the same people as the party activists that coordinate fraud and mobilize voter intimidation.
} 
stations than party agents. During training, observers are instructed to report what they see and it is emphasized that observers are not responsible for what occurs at their polling stations. By contrast, if party monitors are involved in the organization of voter intimidation, they would be more likely to under-report such instances. This would bias against a finding that observers reduce voter intimidation. It may, however, also be the case that some party agents over-report violence in an attempt to paint their competitors in a negative light. To guard against this concern, we only code a station as experiencing intimidation when both respondents, typically party agents from both of Ghana's two major parties, agree that there was intimidation. We find it unlikely that the party agents of both major parties would collude and report violence when none took place.

Second, and importantly, the variation in data collection method is not a relevant concern for our spillover estimates. As we discussed in the previous section, the ASNT estimates are derived from comparisons of outcomes at control stations in each of the three saturation levels. As data from control stations were collected in exactly the same way, we can rule out that the data collection procedure is driving the spillover results. Thus, for the analyses that are of most theoretical interest, concerns about the data collection procedure are not relevant. 
Table 1: Descriptive statistics of manipulation indicators

\begin{tabular}{lccccc}
\hline Indicator & $\begin{array}{c}\text { Full Sample } \\
(1)\end{array}$ & $\begin{array}{c}\text { Control } \\
(2)\end{array}$ & $\begin{array}{c}\text { Treatment } \\
(3)\end{array}$ & $\begin{array}{c}\text { Non-Competitive } \\
(4)\end{array}$ & $\begin{array}{c}\text { Competitive } \\
(5)\end{array}$ \\
\hline Intimidation during voting & 0.07 & 0.12 & 0.05 & 0.06 & 0.09 \\
& $(0.26)$ & $(0.33)$ & $(0.22)$ & $(0.24)$ & $(0.29)$ \\
$\mathrm{N}$ & 1724 & 514 & 1210 & 1007 & 717 \\
Turnout & 0.84 & 0.86 & 0.83 & 0.84 & 0.83 \\
& $(0.24)$ & $(0.30)$ & $(0.21)$ & $(0.23)$ & $(0.26)$ \\
$\mathrm{N}$ & 1794 & 564 & 1230 & 1048 & 746 \\
Outlier $(>\bar{x}+1.96 * S D)$ & 0.03 & 0.05 & 0.02 & 0.02 & 0.03 \\
& $(0.16)$ & $(0.22)$ & $(0.13)$ & $(0.15)$ & $(0.18)$ \\
$\mathrm{N}$ & 1794 & 564 & 1230 & 1048 & 746 \\
Outlier $(>$ Upper Q. $+1.5 *$ IQR $)$ & 0.05 & 0.08 & 0.03 & 0.04 & 0.06 \\
& $(0.21)$ & $(0.27)$ & $(0.18)$ & $(0.20)$ & $(0.23)$ \\
$\mathrm{N}$ & 1794 & 564 & 1230 & 1048 & 746 \\
\hline
\end{tabular}

Note: Table 1 shows the descriptive statistics of our dependent variables. The unit of analysis is the polling station. We report the mean in our full sample, treated and control stations, and for stations located in competitive and non-competitive constituencies. Standard deviations are reported in parentheses. 
Table 1 presents descriptive statistics, displaying means with standard deviations in parentheses. Column 1 shows the summary statistics in our full sample. About 7 percent of stations experienced intimidation during voting. The average turnout rate was 84 percent. About 3 percent of stations have suspiciously high turnout using our first method of measuring outliers, while we code about 5 percent of stations as outliers using the second method. The second and third columns compare control to treatment polling stations. Intimidation occurred in 12 percent of control stations and 5 percent of treated stations, suggesting that observers helped deter violence. Whereas the average turnout rate in treated stations was about 83 percent, it was 86 percent in control stations. Polling stations are also more likely to have suspiciously high turnout rates in the control group: 5 percent in control versus 2 percent in treatment using the first method, and 8 percent in control versus 3 percent in treatment using the second method. Observers thus appear to reduce fraud where they were present.

Columns 4 and 5 display means in competitive and non-competitive constituencies. Levels of intimidation are about 3 percent higher in competitive constituencies ( 9 percent) compared to non-competitive constituencies (6 percent), which is consistent with our argument that there are relatively fewer incentives to engage in electoral violence in single-party dominant areas. Turnout is slightly higher in non-competitive constituencies, which is probably because of greater numbers of partisans who are committed to turnout in party strongholds. Polling stations in competitive areas are also slightly more likely to be coded as outliers using both methods.

\section{Results}

We begin by estimating the intention-to-treat (ITT) effects for our outcomes in the full sample (using Equation 2). Figure 1 displays the ITT estimates as well as 95 percent confidence intervals. Consistent with hypotheses 1 and 2, we find that observers reduce election fraud and intimidation at polling stations where they are deployed. Treatment reduces the probability of voter intimidation during the voting process by 7 percentage points ( 95 percent confidence interval from -11 to -2.7 ). The voter turnout rate in treated stations is 4.5 percentage points lower than it is in control ( 95 
percent confidence interval from -8 to -0.1$)$. In interpreting this result, we emphasize that voter turnout in itself is not undesirable. However, if turnout is significantly different when a randomly assigned observer is present, this is indicative of potential fraud at control stations. Treatment also reduces the probability that a station has a suspiciously high turnout rate, as measured by our outlier measures. The treatment effect using the first method is 3.3 percentage points $(95$ percent confidence interval from -4.4 to -2 ), while it is about 4.7 percentage points using the second method (95 percent confidence interval from -7.2 to -2.2 )

To account for potential biases resulting from observer spillover effects, we estimate our results in keeping with our experimental design. Table 2 presents the means in each cell of our $3 \times$ 2 design. In each constituency-level saturation condition, indicators of fraud and intimidation rates are higher in stations without observers (control) than stations with observers (treated). For example, turnout is between 85 and 89 percent in control polling stations in each saturation condition, while it is between 82 and 85 percent in treated polling stations. The percentage of stations that experience intimidation is between 8 and 18 percent in control stations, and between 4 and 7 percent in treated stations, across each level of observer saturation.

Table 2 also presents the spillover-corrected ITT estimates, ITT $(s)$, which show that, when accounting for spillover, observers reduce fraud and violence in polling stations where they are deployed. Our estimates show that observers reduce the likelihood of intimidation of voters during voting. The ITT(s) is 5 percentage points in the low condition, 4 percentage points in medium condition, and 6 percentage points in high saturation condition. The treatment effects in the low, medium and high treatment conditions are all statistically significant at the 5 percent level. The ITT(s) for turnout is 4 percentage points in the low condition, 7 percentage points in the medium condition, and 6 percentage points in the high condition. ${ }^{82}$ While the effect of observers is not statistically significant in the low saturation condition, effects are significant in the medium and high saturation conditions. We uncover similar results when we analyze the outlier measures.

${ }^{82}$ While the ITT(s) is higher in the middle saturation, the effect is not statistically different from the effects in the low and high saturation conditions. 
These results provide further evidence in support of hypotheses 1 and 2 . 
Figure 1: Direct Effect of Observers in Full Sample

Notes: Figure 1 shows intention-to-treat (ITT) effects of observers. Our unit of analysis is the polling station. In estimating all quantities of interest, we use inverse probability weighting. We use randomization inference to calculate the 95 percent confidence bounds around these estimates. Specifically, we assume that the estimated effect is same for all units and use that to generate hypothetical potential outcomes for each unit (Gerber and Green, 2012). When simulating possible random allocation of treatment, we cluster on constituency. 
Table 2: Observers' effect on election day manipulation

\begin{tabular}{|c|c|c|c|}
\hline \multirow[b]{2}{*}{ Indicator } & \multicolumn{3}{|c|}{ Treatment saturation } \\
\hline & Low & Middle & High \\
\hline \multicolumn{4}{|l|}{ Intimidation during voting } \\
\hline \multirow[t]{2}{*}{ Treated } & 0.05 & 0.07 & 0.04 \\
\hline & $(0.02)$ & $(0.01)$ & $(0.01)$ \\
\hline \multirow[t]{2}{*}{ Control } & 0.10 & 0.15 & 0.08 \\
\hline & $(0.03)$ & $(0.02)$ & $(0.03)$ \\
\hline ITT(s) & -0.05 & -0.04 & -0.06 \\
\hline Standard error & $(0.03)$ & $(0.03)$ & $(0.03)$ \\
\hline \multicolumn{4}{|l|}{ Turnout } \\
\hline \multirow[t]{2}{*}{ Treated } & 0.85 & 0.82 & 0.83 \\
\hline & $(0.01)$ & $(0.01)$ & $(0.01)$ \\
\hline \multirow[t]{2}{*}{ Control } & 0.89 & 0.85 & 0.86 \\
\hline & $(0.02)$ & $(0.02)$ & $(0.02)$ \\
\hline ITT(s) & -0.04 & -0.07 & -0.06 \\
\hline Standard error & $(0.03)$ & $(0.02)$ & $(0.02)$ \\
\hline \multicolumn{4}{|l|}{ Outlier $(>\bar{x}+1.96 * S D)$} \\
\hline Treated & $\begin{array}{l}0.02 \\
(0.01)\end{array}$ & $\begin{array}{l}0.02 \\
(0.01)\end{array}$ & $\begin{array}{l}0.01 \\
(0.01)\end{array}$ \\
\hline \multirow[t]{2}{*}{ Control } & 0.05 & 0.05 & 0.06 \\
\hline & $(0.02)$ & $(0.01)$ & $(0.02)$ \\
\hline ITT(s) & -0.03 & -0.03 & -0.03 \\
\hline Standard error & $(0.02)$ & $(0.02)$ & $(0.02)$ \\
\hline \multicolumn{4}{|l|}{ Outlier (> Upper O. + 1.5*IOR) } \\
\hline \multirow[t]{2}{*}{ Treated } & 0.04 & 0.04 & 0.03 \\
\hline & $(0.01)$ & $(0.01)$ & $(0.01)$ \\
\hline \multirow[t]{2}{*}{ Control } & 0.08 & 0.08 & 0.08 \\
\hline & $(0.02)$ & $(0.02)$ & $(0.03)$ \\
\hline ITT(s) & -0.04 & -0.04 & -0.05 \\
\hline Standard error & $(0.03)$ & $(0.02)$ & $(0.02)$ \\
\hline
\end{tabular}

Note: Table 2 reports mean estimates for our dependent variables in each of our six treatment conditions. In estimating means, each unit is weighted by the inverse of its treatment probability. Standard errors are reported in parentheses. Table 2 also shows the spillover-corrected ITT at each level of observer saturation with their standard errors reported in parentheses. We also report the pvalues from a two-sided t-test of these estimates. 
To test hypotheses 3 and 4, we present spillover effects in electorally competitive and single-party dominant constituencies. Figures 2 and 3 present the results. The points in the plots are calculated by estimating Equation 4 separately in competitive and non-competitive constituencies. We present the numerical results in Online Appendix C.

Figure 2 presents our findings on election-day intimidation. Consistent with hypothesis 4 , we find evidence of displacement in competitive constituencies (depicted in the left plot). In competitive constituencies, voter intimidation is 24.3 percentage points more likely in control stations in the medium saturation relative to control stations in low saturation constituencies. In the high saturation, voter intimidation is 9.8 percentage points more likely to occur. Both of these estimates are statistically significant at the 5 percent level. In non-competitive constituencies (shown in the right plot), the pattern is reversed. The incidence of voter intimidation is reduced by 11 percent and 12.3 percent in control stations in medium and high saturation conditions respectively, relative to control stations in low saturation condition. Both estimates are statistically significant. ${ }^{83}$ These results suggest that observers displace violence and intimidation in competitive constituencies, but deter them in single-party dominant areas.

Figure 3 presents results for the indicators of fraud. In non-competitive areas, the ASNTs in the medium condition are all very close to zero. Examining the outlier measures, the ASNTs in the high saturation condition are positive, which is consistent with hypothesis 3. For example, controls in high saturation are 2.4 percentage points more likely to have suspiciously high turnout than controls in low saturation when we analyze the second method coding outliers. These results are, however, statistically weak and further research is required to corroborate hypothesis 3 .

\footnotetext{
${ }^{83}$ While our theory emphasizes that there is relatively less incentive to engage in violence or intimidation in party strongholds, we are not arguing that there will be no violence or intimidation in these constituencies. Consistent with this, Table 1 shows that there is some violence and intimidation in strongholds, but that this strategy occurs more frequently in competitive constituencies. Thus, it is possible for observers to deter violence and intimidation in strongholds.
} 
The pattern in competitive constituencies is different. For example, in control stations, turnout is reduced by about 6 percentage points in the medium and 7 percentage points in the high saturations compared to the low saturation condition. While these estimates are not statistically significant at conventional levels, the point estimates suggest that observers may deter fraud in control stations when deployed in large numbers to non-competitive constituencies. Taken together, these patterns are consistent with the argument that the local context conditions how political parties respond to the presence of election observers.

Finally, we conduct a constituency level analysis in which we examine the impact of increasing the saturation of observers on overall levels of fraud and violence in a constituency. These results are presented in Online Appendix F. In the full sample, increasing the share of polling stations with observers leads to statistically significant decreases in overall levels of fraud and violence. In electorally competitive constituencies, increasing the saturation of observers decreases overall levels of fraud but has no impact on levels of violence and intimidation. In noncompetitive areas, increasing the saturation of observers has relatively little impact on overall levels of fraud, but a substantial negative effect on levels of violence and intimidation. These results are consistent with the patterns of spillover documented above, and demonstrate how the local electoral context conditions the overall impact of observers. 
Figure 2: Average Spillover Effect on Non-Treated Stations: Intimidation

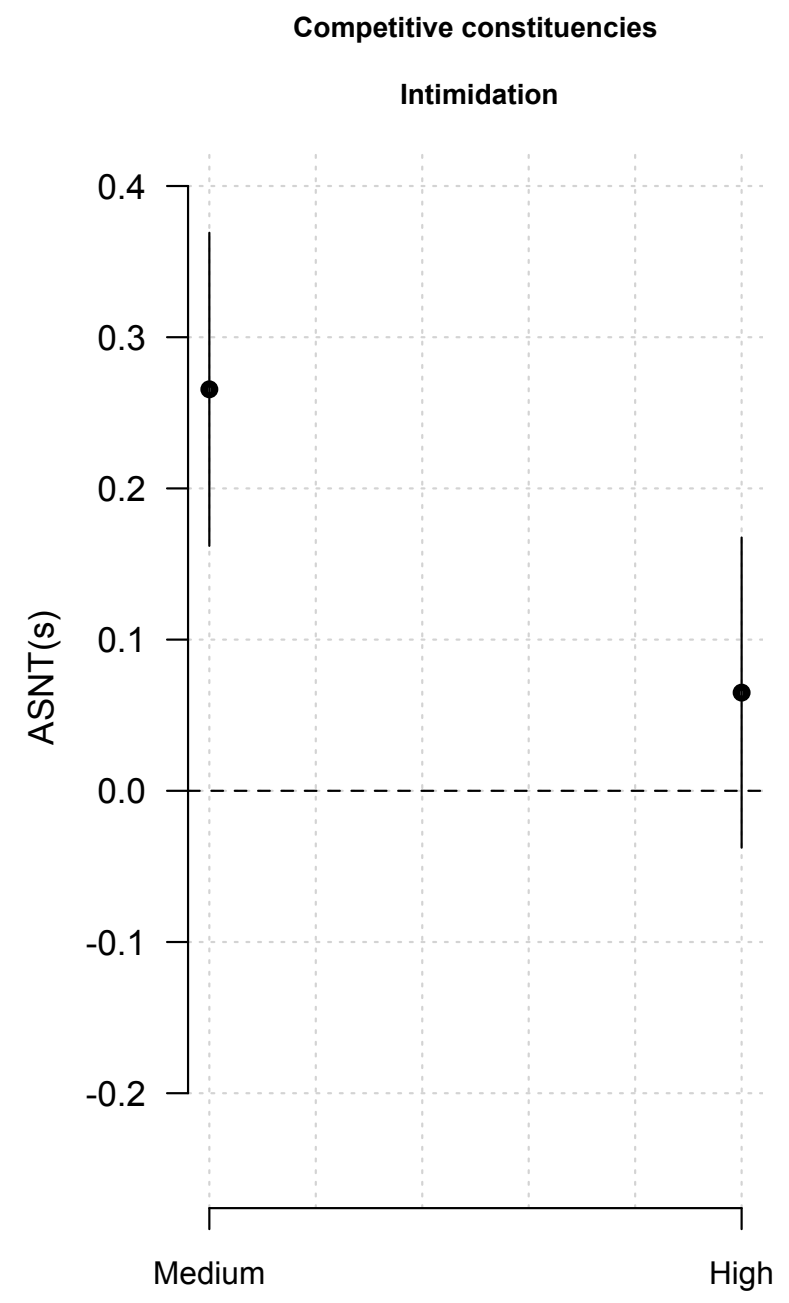

\author{
Non-competitive constituencies \\ Intimidation
}
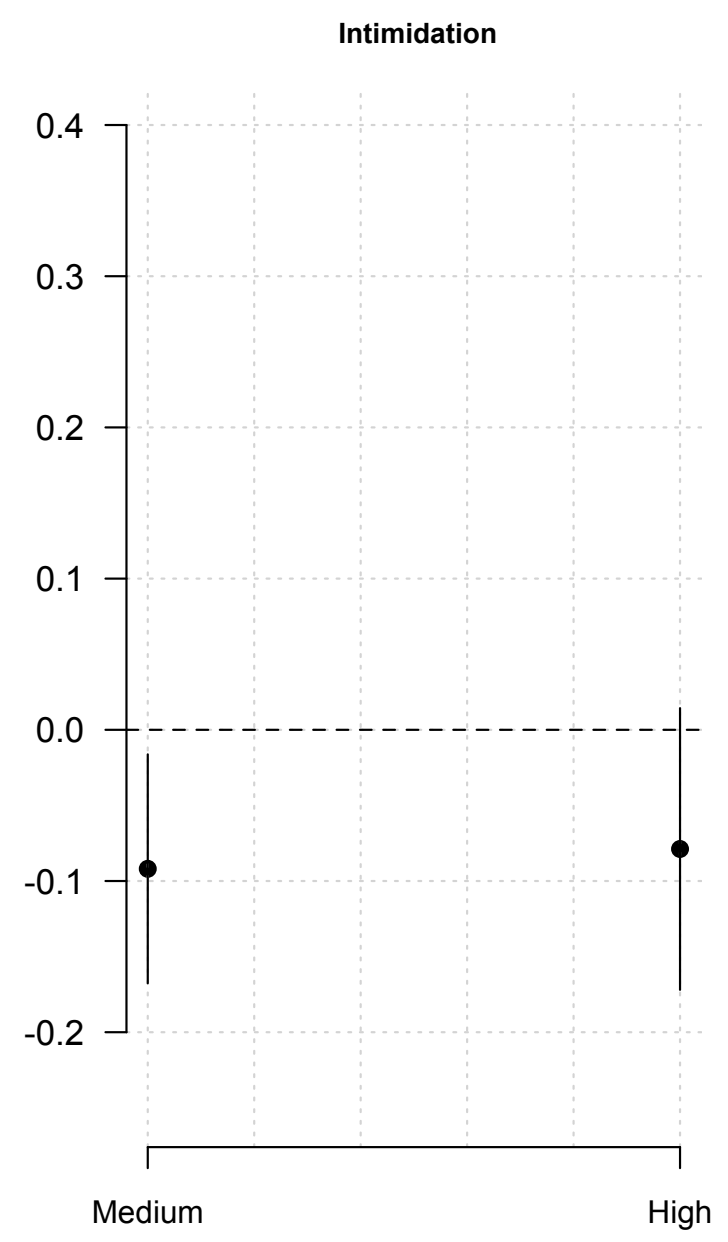

Notes: Figure shows the average spillover on the non-treated $(A S N T(s))$ of observers on turnout and intimidation during voting in competitive and non-competitive constituencies. Our unit of analysis is the polling station. In estimating the $A S N T(s)$, we use inverse probability weighting. We use randomization inference to calculate the 95 percent confidence bounds around these estimates. Specifically, we assume that the estimated effect is same for all units and use that to generate hypothetical potential outcomes for each unit (see Gerber and Green 2012). When simulating possible random allocation of treatment, we cluster on constituency. 


\section{Figure 3: Average Spillover Effect on Non-Treated Stations: Fraud}
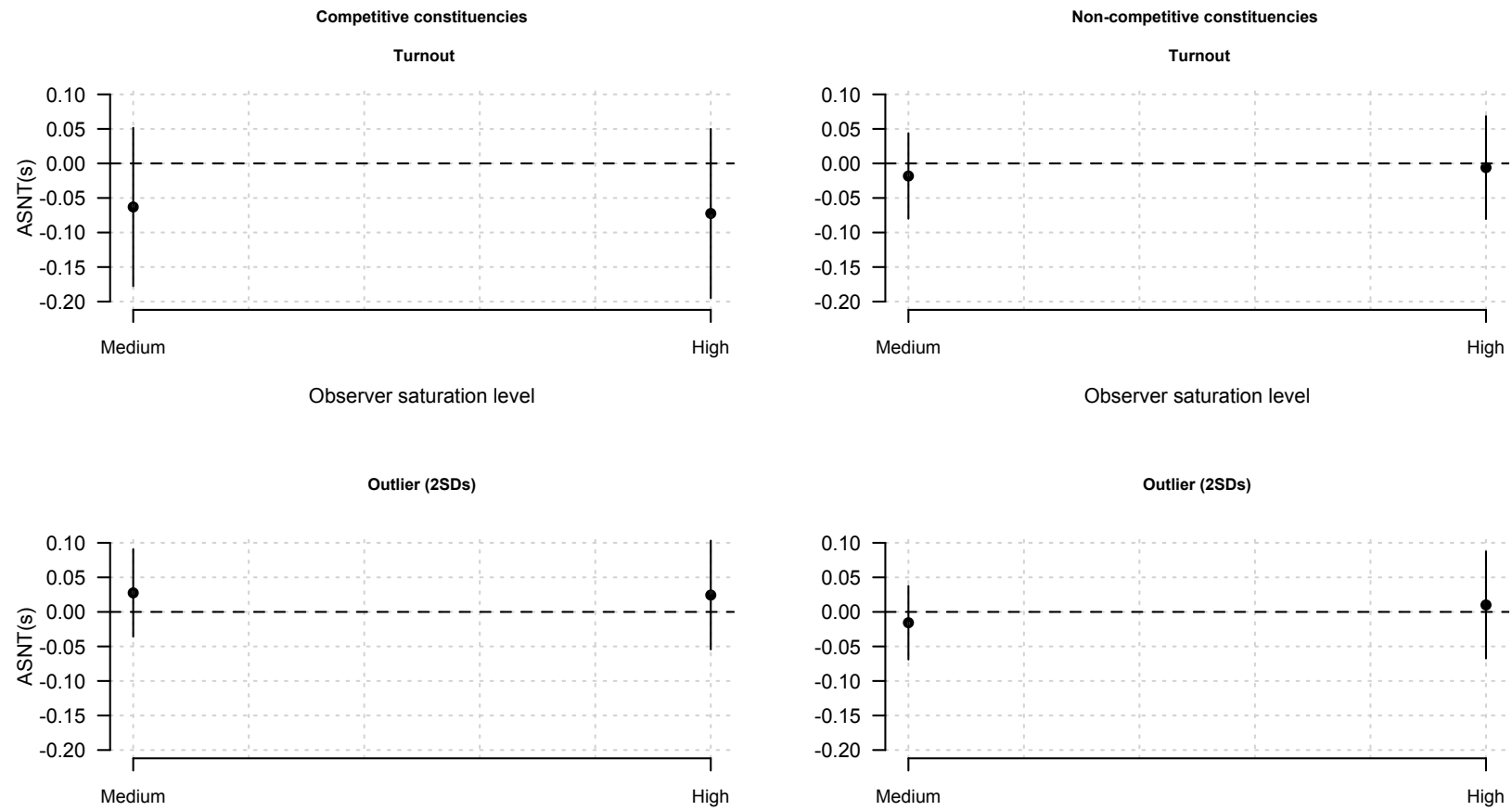

Outlier (IQR)
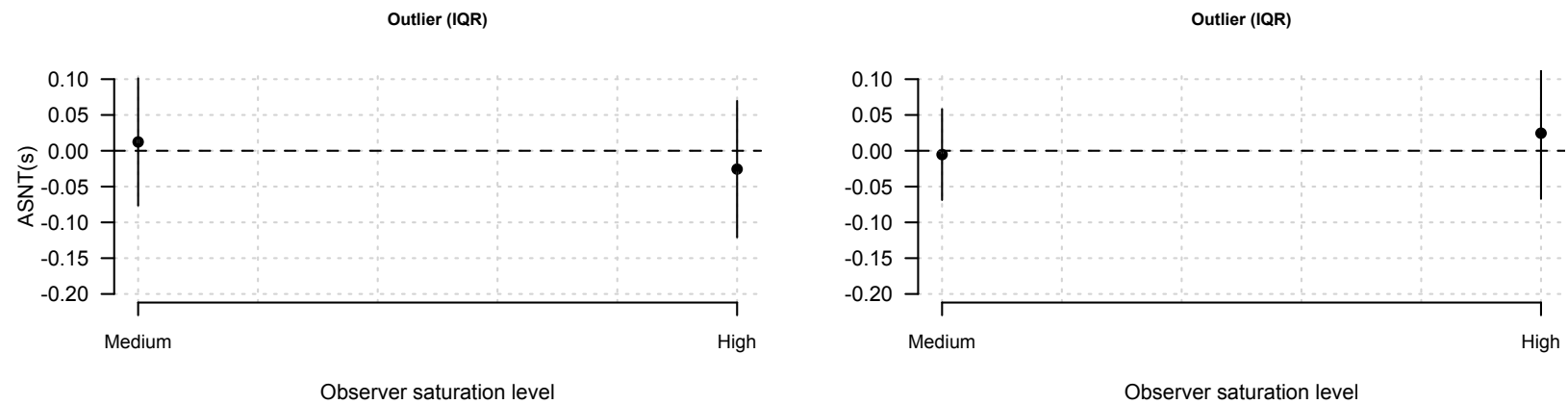

Notes: Figure shows the average spillover on the non-treated $(A S N T(s))$ of observers on turnout and intimidation during voting in competitive and non-competitive constituencies. Our unit of analysis is the polling station. In estimating the $A S N T(s)$, we use inverse probability weighting. We use randomization inference to calculate the 95 percent confidence bounds around these estimates. Specifically, we assume that the estimated effect is same for all units and use that to generate hypothetical potential outcomes for each unit (see Gerber and Green 2012). When simulating possible random allocation of treatment, we cluster on constituency. 


\section{Discussion}

We present evidence of electoral fraud and violence and intimidation during Ghana's 2012 election. Our findings show that the presence of a domestic election observer at a polling station significantly reduces both of these forms of electoral malfeasance. Our results also show that political parties are not passive to the deployment of observers. Consistent with our framework, we find evidence that how parties respond to election observers is not uniform across constituencies. We find strong evidence that parties respond to observers by displacing violence to control stations in competitive constituencies. In contrast, in single-party dominant constituencies, parties choose to shift fraud to control stations, although the strength of the evidence is weaker than the evidence on intimidation. To account for these differences, we emphasize that opportunities to commit fraud and incentives to engage in election violence vary across electoral environments.

While our findings are consistent with our framework, they also show that when observers are deployed at higher rates in non-competitive constituencies, they deter party activists from engaging in violence at control stations. Further research is required to understand the mechanism driving this result. It may be that a high concentration of election observers increases the perceived costs of intimidation to parties in their stronghold areas. Because observers are likely to publicize instances of violence, parties risk alienating their core support groups if they are caught engaging in the strategy, especially in their stronghold areas.

Since electoral competition is not randomly assigned to constituencies, it may be that other constituency characteristics, which correlate with competition, are driving these differential patterns of spillover. Although we cannot completely rule out this possibility, the data we have do not suggest any major differences across competitive and non-competitive constituencies. Online Appendix D presents data on indicators of economic development and public infrastructure in competitive and non-competitive constituencies. Both types of constituencies have comparable road networks, rates of electrification, and shares of individuals living in poverty. Finally, the number of polling stations per square kilometer, which measures the average distance between stations, is comparable in competitive and non-competitive areas. In short, infrastructure, urbanization, and 
development do not differ across competitive and non-competitive constituencies. These differences are therefore unlikely to explain the patterns of differential spillover that we find.

\section{Conclusion}

Our results corroborate previous research that finds that election observers reduce electoral fraud. We extend this literature by investigating the effects of domestic observers on electoral fraud and election-related violence in one study. In addition, we explicitly account for potential spillover effects in our estimation of the causal impact of observers and analyze how spillover effects vary across different political contexts and across strategies of malfeasance. Analyzing spillover effects advances understanding of how local electoral context shapes the strategies that political parties adopt to manipulate electoral outcomes. More specifically, our results show that electoral competitiveness is not sufficient to explain when parties in a democratic context will seek to engage in fraud. Our findings suggest that opportunities are also important. In addition, our results suggest that election-day violence is likely to occur where electoral competition is intense and where parties lack opportunities to engage in fraud, either because civil society blocked opportunities for fraud or because parties lack the organizational capacity and penetration of local political and social networks that is often required to engage in fraud.

Our study examines a single election in one country. The advantage of this approach is that it allows us to generate well-identified estimates of observers' direct and spillover effects. This microlevel analysis is a crucial complement to macro-level investigations, which are often limited in their ability to identify causal effects. A relative limitation of our approach is external validity. In many ways, however, Ghana is a typical case and so we expect our findings to generalize to other similar democracies in Africa and beyond. Like many countries in Africa and elsewhere, Ghana is a young and not yet fully consolidated democracy with a history of elections that have been marred by allegations of fraud and instances of voter intimidation. Ghana is also characterized by many of the political and institutional factors that the literature suggests create incentives for fraud and violence. 
For example, partisan electoral competition is intense ${ }^{84}$ and the country has a majoritarian, singlemember-district electoral system. ${ }^{85}$ As in many countries in Africa, institutions of horizontal accountability, such as parliament, are relatively weak, and political power is concentrated in the office of the executive president. As a result, presidential elections are high-stakes contests and the perceived benefits of victory may incentivize electoral manipulation. If observers reduce malfeasance in this environment, where incentives for fraud and intimidation are strong, we would expect them to have similar or even stronger effects where incentives to commit fraud or engage in violence are weaker.

Ghana is also distinct in other ways that may limit the generalizability of our findings. First, CODEO is a professional and neutral organization, and is perceived as such domestically. Observer groups in other countries may have less capacity and may themselves be subject to political cooptation, which would attenuate the effects of observers. Second, Ghana has a vibrant press and a vigilant civil society committed to the promotion of democracy. Media and civil society groups are likely to amplify the impact of observers by reporting and publicizing observer reports. Observers' effects may be weaker where these societal forces are less robust.

Our results suggest a number of directions for future research. First, while we document that observers reduce fraud and violence, we do not pin down the precise mechanism through which observers have this effect. Research designs that better identify the mechanisms driving observer effectiveness will be useful. Investigating more closely how party brokers commit and coordinate manipulative strategies and how electoral officials are hired and co-opted may also be fruitful avenues of future research. An investigation of the types of legal, organizational, and psychological interventions that could improve the professionalization of poll workers would advance our understanding of how fraud works and how bureaucratic reform might limit it.

Finally, this paper makes several contributions. First, we provide empirical evidence that domestic election observers in a low-income democracy are capable of limiting multiple forms of

\footnotetext{
${ }^{84}$ Lehoucq 2002.

${ }^{85}$ Birch 2007; Hicken 2007.
} 
electoral malfeasance. These findings highlight the important role of local civil society in advancing democratic consolidation. Second, we investigate how spillover effects vary across political contexts and forms of electoral malfeasance in order to learn about how the local political environment influences patterns of electoral fraud and election-related violence. These findings advance our understanding of how political parties select from the diverse "menu of manipulation" in different political environments on election day. Finally, this paper has methodological implications. We provide an applied example of the randomized saturation experimental design, ${ }^{87}$ which may prove useful in other applications where spillover effects are likely.

\footnotetext{
${ }^{86}$ Schedler 2002.

${ }^{87}$ Baird et al. 2014.
} 


\section{References}

Amankwaah, Clementina. 2013. "Election-Related Violence: The Case of Ghana." Current African Issues, Nordiska Afrikaininstitutet 56.

Baird, Sarah, J Aislinn Bohren, Craig McIntosh and Berk Ozler. 2014. "Designing Experiments to Measure Spillover Effects.” World Bank Policy Research Working Paper (6824).

Beber, Bernd and Alexandra Scacco. 2012. "What the numbers say: A digit-based test for election fraud." Political analysis 20(2):211-234.

Birch, Sarah. 2007. "Electoral Systems and Election Misconduct." Comparative Political Studies 40(12):1533-56.

Boafo-Arthur, Kwame. 2006. The 2004 General Elections: An Overview. In Voting for Democracy in Ghana: The 2004 Elections in Perspective, ed. Kwame Boafo-Arthur. Vol. 1 Freedom Publications.

Bob-Milliar, George M. 2012. "Political party activism in Ghana: Factors influencing the decision of the politically active to join a political party." Democratization 19(4):668-89.

Bratton, Michael. 2008. "Vote Buying and Violence in Nigerian Election Campaigns.” Electoral Studies 27(4):621-32.

Callen, Michael and James D. Long. 2015. "Institutional Corruption and Election Fraud: Evidence from a Field Experiment in Afghanistan.” American Economic Review 105(1):354-81.

Collier, Paul and Pedro C. Vicente. 2012. "Violence, Bribery, and Fraud: The Political Economy of Elections in Sub-Saharan Africa." Public Choice 153(1-2):117-47.

Collier, Paul and Pedro C Vicente. 2013. "Votes and Violence: Evidence from a Field Experiment in Nigeria." Economic Journal .

Deckert, Joseph, Mikhail Myagkov and Peter C Ordeshook. 2011. "Benford's Law and the 
detection of election fraud." Political Analysis 19(3):245-268.

Enikolopov, Ruben, Vasily Korovkin, Maria Petrova, Konstantin Sonin and Alexei Zakharov. 2013.

"Field Experiment Estimate of Electoral Fraud in Russian Parliamentary Elections."

Proceedings of the National Academy of Sciences 110(2):448-452.

European Union. 2009. Ghana Final Report: Presidential and Parliamentary Elections 2008.

Technical report European Union Election Observation Mission.

Frazer, Jendayi and Emmanuel Gyimah-Boadi. 2011. Preventing Electoral Violence in Africa. Carnegie Mellon: Carnegie Mellon.

Fridy, Kevin. 2007. “The Elephant, Umbrella, and Quarrelling Cocks: Disaggregating Partisanship in Ghana's Fourth Republic." African Affairs 106(423): 281-305.

Gerber, Alan and Donald Green. 2012. Field Experiments: Design, Analysis, and Interpretation. New York: W.W. Norton.

Gyimah-Boadi, E and V Brobbey. 2012. "Countries at the Crossroads: Ghana." Freedom House .

Hafner-Burton, Emilie M, Susan D Hyde and Ryan S Jablonski. 2014. "When Do Governments Resort to Election Violence?" British Journal of Political Science 44(01):149-179.

Hicken, Allen. 2007. How do rules and institutions encourage vote buying? In Elections for Sale: The Causes and Consequences of Vote Buying, ed. Frederic Charles Schaffer. New York: Cambridge University Press pp. 47-60.

Hyde, Susan D. 2007. "The Observer Effect in International Politics: Evidence From a Natural Experiment." World Politics 60(1):37-63.

Hyde, Susan D. 2010. "Experimenting in Democracy: International Observers and the 2004 Pesidential Elections in Indonesia." Perspectives on Politics 8(2):511-27.

Hyde, Susan D. 2011. The Pseudo-Democrat's Dilemma: Why Election Observation Became an International Norm. Cornell University Press. 
Ichino, Naomi and Matthias Schündeln. 2012. "Deterring or Displacing Electoral Irregularities? Spillover Effects of Observers in a Randomized Field Experiment in Ghana." Journal of Politics 74(1):292-307.

Jockers, Heinz, Dirk Kohnert and Paul Nugent. 2010. “The successful Ghana election of 2008: A convenient myth?” The Journal of Modern African Studies 48(1):95-115.

Kelley, Judith. 2011. "Data on International Election Monitoring: Three Global Datasets on Election Quality, Election Events and International Election Observation.” ICPSR1461-v1. Ann Arbor, MI: Inter-university Consortium for Political and Social Research.

Kelley, Judith G. 2012. Monitoring Democracy: When International Election Observation Works, and Why It Often Fails. Princeton: Princeton University Press.

Lehoucq, Fabrice. 2003. "Electoral Fraud: Causes, Types, and Consequences.” Annual Review of Political Science 6:233-56.

Lehoucq, Fabrice Edouard. 2002. Stuffing the ballot box: Fraud, electoral reform, and democratization in Costa Rica. Cambridge University Press.

Lindberg, Staffan I. and Minion K.C Morrison. 2008. "Are African voters really ethnic or clientelistic? Survey evidence from Ghana.” Political Science Quarterly 123(1):95-122.

Molina, Iván and Fabrice Edouard Lehoucq. 1999. "Political Competition and Electoral Fraud: A Latin American Case Study.” Journal of Interdisciplinary History 30(2):199-234.

Moore, David S. and George P McCabe. 2004. Introduction to the Practice of Statistics, 5th edition. New York: W. H. Freeman.

Osei, Anja. 2012. Party-Voter Linkage in Africa: Ghana and Senegal in Comparative Perspective. Springer.

Robinson, James A and Ragnar Torvik. 2009. “The Real Swing Voter's Curse.” The American Economic Review 99(2):310. 
Salih, Mohamed and Per Nordlund. 2007. Political Parties in Africa: Challenges for Sustained Multiparty Democracy. Regional Report 2007 IDEA International IDEA: .

Schedler, Andreas. 2002. “The menu of manipulation.” Journal of Democracy 13(2):36-50.

Sjoberg, Fredrik M. 2012. "Making Voters Count: Evidence from Field Experiments about the Efficacy of Domestic Election Observation.” Unpublished paper.

Smith, Daniel A. 2002. “Consolidating Democracy? The Structural Underpinnings of Ghana's 2000 Elections." The Journal of Modern African Studies 40(4):621-50.

Snyder, Mark. 1987. Public Appearance/Private Realities. New York: Freeman.

Stokes, Susan C., Thad Dunning, Marcelo Nazareno and Valeria Brusco. 2013. Brokers, Voters, and Clientelism: The Puzzle of Distributive Politics. New York: Cambridge University Press.

Straus, Scott and Charlie Taylor. 2012. Democratization and Electoral Violence in Sub-Saharan Africa, 1990-2008. In Voting in Fear, ed. Dorina A. Bekoe. Washington, D.C.: United States Institute of Peace.

Tucker, Joshua A. 2007. "Enough! Electoral fraud, collective action problems, and postcommunist colored revolutions." Perspectives on Politics 5(03):535-551.

Weghorst, Keith R. and Staffan I. Lindberg. 2013. "What Drives the Swing Voter in Africa?" American Journal of Political Science 57(3):717-43.

Weidmann, Nils B. and Michael Callen. 2013. "Violence and Election Fraud: Evidence from Afghanistan." British Journal of Political Science 43(01):53-75.

Whitfield, Lindsay. 2009. “'Change for a Better Ghana': Party Competition, Institutionalization and Alternation in Ghana's 2008 Elections." African Affairs 108(433):621-41.

Wilkinson, Steven I. 2004. Votes and Violence: Electoral Competition and Ethnic Riots in India. Cambridge: Cambridge University Press.

Ziblatt, Daniel. 2009. "Shaping Democratic Practice and the Causes of Electoral Fraud: The Case 
of Ninteenth-Century Germany." American Political Science Review 103(1):1-21. 